Derleme Makalesi/Review Article

\title{
Bilecik İli Yem Bitkilerinin Mevcut Durumu
}

\author{
Abdulmuttalip MEŞE ${ }^{1}$, Erdem GÜLÜMSER ${ }^{2 *}$, Hanife MUT $^{3}$ \\ Geliş / Received: 12/09/2019 \\ Revize / Revised: 12/11/2019 \\ Kabul / Accepted: 15/11/2019
}

\begin{tabular}{l}
\hline ÖZ \\
\hline Hayvancılığın vazgeçilmez besin kaynaklarından biri de kaba yemlerdir. Bilecik ilinde 6.008 hektar çayır mera \\
varlığından ve yem bitkileri ekilişlerinden toplam 69.344 ton kuru ot üretimi sağlanmaktadır. İlde 44.997 BBHB \\
mevcut olup, gerekli kaliteli kaba yem ihtiyacı ise 205.302 tondur. Buna göre, ilde kaba yem açı̆̆ 135.958 ton \\
iken, ihtiyacın ancak \% 33.77'si karşılanabilmektedir. Bilecik, 125.080 hektar işlenebilir tarım alanına sahip \\
olup, bu alan içerisindeki yem bitkileri ekiliş miktarı ise 6.626 hektardır. Amaç, ilin mevcut kaba yem ihtiyacının \\
karşılanabilmesi için yem bitkileri ekiliş miktarı ile çayır mera alanlarının verimini ve kalitesini arttırabilmektir. \\
Sorunların aşılabilmesi için öncelikle hayvan yetiştiricilerinin kaliteli kaba yemin hayvansal üretimdeki yerini \\
kavramaları gerekmektedir. Böylelikle yem bitkileri, nadas alanlarının daraltılması ile münavebeye dâhil \\
edilebilir, kaliteli bir üretim için sertifikalı tohumluk kullanımı arttırılabilir, çayır mera alanları üzerindeki \\
otlatma baskısı azaltılarak daha fazla ve kaliteli üretim sağlanabilir. Ayrıca, Tarım ve Orman Bakanlığı, yem \\
bitkilerinin desteklenmesinde karşılaşılan engelleri kaldırılması durumunda, Bilecik ilinde kaba yem üretiminin \\
istenilen seviyeye ulaşması mümkün olacaktır.
\end{tabular}

Anahtar Kelimeler-Bilecik, Yem Bitkileri, Çayır, Mera, Sorunlar

\footnotetext{
1İletişim: abdulmuttalip.mese@tarımorman.gov.tr (https://orcid.org/0000-0002-2229-021X) Bilecik İl Tarım ve Orman Müdürlügü, Merkez, Bilecik

${ }^{2 *}$ Sorumlu yazar iletişim: erdem.gulumser@bilecik.edu.tr (https://orcid.org/0000-0001-6291-3831)

Tarla Bitkileri Bölümü, Bilecik Şeyh Edebali Üniversitesi, Gülümbe Kampüsü, Merkez, Bilecik

3Illetişim: hanife.mut@bilecik.edu.tr (https://orcid.org/0000-0002-5814-5275)

Tarla Bitkileri Bölümü, Bilecik Şeyh Edebali Üniversitesi, Gülümbe Kampüsü, Merkez, Bilecik
} 


\title{
Current Status of Forage Crops in Bilecik Province
}

\begin{abstract}
The roughages are one of the indispensable feed sources of livestock. In the Bilecik province, a total of 69.344 tons hay is produced from the meadow, pastures (6.008 ha) and forage crops. There are 44.997 animal units in the city, and they need annually 205.302 ton good quality hay. In the Bilecik province, the roughage deficit is 135.958 tons, and only $33.77 \%$ can be met. Total arable land in the province is 125.080 hectares and, forage crops are cultivated on 6.626 hectares in this area. The aim is to increase the quantity and quality of roughage production of grasslands and forage crops to meet the current hay needs in the province. To overcome the problems, all ruminant farmers should aware of the importance of roughage to livestock. So, forage crops can be included in the crop rotation by narrowing the fallow areas, the use of certified seeds for quality production can be increased, and the grazing pressure on the pasture areas can be reduced and more and more quality product can be achieved. Besides, it will be possible to achieve the desired level of forage crops production in the province, if the Ministry of Agriculture and Forestry obstacles encountered in the support of forage crops are removed.
\end{abstract}

\section{Keywords- Bilecik, Forage Crops, Meadow, Pasture, Problem.}




\section{GíRiş}

Dünyada ve ülkemizde insan beslenmesinde vazgeçilmez olan hayvansal ürünlerin yüksek kaliteli ve kolay ulaşılabilir olması insanların hayatlarını kaliteli bir şekilde devam ettirmeleri ve nesillerini sürdürmeleri açışından oldukça önemlidir. Bu anlamda hayvansal üretimin masrafların büyük bir kısmını oluşturan yemin daha ucuz ve hayvanların ihtiyaçlarını karşılayacak düzeyde kaliteli olması gerekmektedir. Hayvancılıkta ihtiyaç duyulan kaba yemler genel anlamda çayır meralardan ve tarla tarımı içerisinde yetiştirilen yem bitkilerinden sağlanmaktadır. Kaba yemlerin en ucuz ve kolay şekilde temininin sağlandığı çayır ve meralar, uzun yıllardır bilinçsiz ve ağır şekilde otlatılmaları ve mera amenajman kurallarına uyulmaması sebebi ile tahrip olmuşlardır. $\mathrm{Bu}$ yem alanlarının kullanma ve çevre faktörlerine bağlı olarak kaliteleri düşmüş ve daha az yem üretir hale gelmişlerdir [1]. Diğer bir kaynak olan yem bitkileri tarımı ise hayvanların ihtiyaçları için hala yetersiz düzeydedir [2].

Öte yandan hayvanların fizyolojik gereksinimleri dikkate alındığında ve ekonomik getirisi düşünüldüğünde, elde edilecek ürünün besin madde içeriği ile yedirilecek yemin denge içerisinde olması gerekmektedir. Nitekim ülkemizde kaba yem temininde hayvanların beslenmesinden ziyade sadece doyurmak amaciyla kullanılan ve yedirildiklerinde zor sindirilmeleri nedeni ile enerji kaybına sabep olan saman gibi tarla atıkları hala hayvan beslenmesinde önemli bir yer işgal etmektedir [3]. Dolayısıyla, bu durum saman fiyatlarını yükseltirken, hayvansal verimin de düşmesine sebep olmaktadır. Hayvancılıkta ekonomik ve sürdürülebilir işletmelerin kurulabilmesi için kullanılacak kaliteli kaba yem maliyetlerini mutlaka düşürülmesi gerekmektedir [4]. Ülkemizde 2018 yılı Türkiye İstatistik Kurumu verilerine göre, toplam tarım alanları 23.1 milyon ha, toplam işlenen tarım alanı 15.4 milyon hektar ve nadas alanları ise 3.513 milyon hektardır. Toplam işlenen tarım alanlarının büyük bir kısmını tahıl bitkileri oluşturmakta, yem bitkileri üretimi toplam tarım alanlarının yaklaşık \% 8'ini (1.9 milyon ha) kapsamaktadır. Çayır ve mera alanlarımız ise 14.617 milyon hektardır [5]. Buna göre söz konusu yılda toplam BBHB ise 19.042.278 civarında olup, yıllık ihtiyaç duyulan kaliteli kaba yem yaklaşık 86 milyon ton olarak karşımıza çıkmaktadır. Çayır meralar ve yem bitkileri üreminden karşılanan kaba yem miktarı ise yaklaşık olarak 31 milyon ton civarındadır. Bu verilere göre ülkemizde hayvanların yem ihtiyacı mevcut kaba yem üretimi ile karşılanmamaktadır. Bu kapsamda kaba yem gereksinimini karşılamak için çayır ve meraların ıslah edilmesi, yem bitkisi üretim alanlarının artırılması, alternatif kaba yem kaynaklarının hayvansal üretime kazandırılması ve kaliteli kaba yem üretim tekniklerinin üreticilere aktarılması gerekmektedir. Ayrıca ekolojik farklılıklar dikkate alınarak bölge bazlı üretim ile sürdürülebilirliği sağlamak ise bitkisel ve hayvansal üretimin temel unsurudur.

Yukarıdaki açıklamalara göre hayvancılık girdilerinin büyük bir kısmını oluşturan yem maliyetlerinin (yaklaşık olarak \% 60-70) önüne geçebilmek ve birim alandan alınabilecek verimin yükseltilmesi için kaba yem kaynağı olan yem bitkileri üretiminin artırılması yadsınamaz bir gerçektir.

$\mathrm{Bu}$ derleme ile Bilecik ilinde yem bitkilerinin mevcut durumu incelenerek, ulusal literatüre katkı sağlanması amaçlanmıştır.

\section{BILEECIK İLİ ARAZİ VARLIĞI VE KULLANIM DURUMU}

Türkiye'de toprak genişliği bakımından 70. sırada yer alan Bilecik 430.700 hektar yüzölçümüne sahiptir. İlde toplam işlenebilir tarım arazisi varlığ 125.080 hektar olup, bu alanın 42.015 hektarında (\% 33.59) sulu tarım, 83.065 hektarında (\% 66.41) kuru tarım yapılmaktadır. İlin çayır mera varlığı 6.008 hektar ile toplam arazi varlığının \% 1.4'ünü, orman alanları ise 228.641 hektar ile \% 53.08'ini oluşturmaktadır [6]. (Tablo 1). 
Tablo 1. Bilecik ili arazi varlı̆̆ ${ }^{*}$

\begin{tabular}{lcc}
\hline Kullanım Şekli & Alanı (ha) & Oranı (\%) \\
\hline İşlenen Arazi & 125.080 \\
Çayır-Mera & 6.008 & 29.04 \\
Orman Arazisi & 228.641 & 1.4 \\
Yerleşim Alanları ve Tarıma Elverişsiz Alanlar & 70.969 \\
Toplam & 430.700 \\
\hline * Bilecik İli 2018 yılı Tarım ve Orman Müdürlüğü Brifingi & 16.48 \\
\hline
\end{tabular}

* Bilecik İli 2018 yılı Tarım ve Orman Müdürlüğü Brifingi

\section{A. Yetiştirilen ürün gruplarl ve üretimleri}

İlde toplam tarım alanlarının \% 40.5'inde tarla tarımı yapılmakta olup, bu alan 50.725 hektar ile toplam tarım alanının oldukça büyük bir kısmını oluşturmaktadır. Hububat ekim alanı ise tarla tarımı yapılan alanın yaklaşık \% 80'ini oluşturmaktadır. Bunu \% 7 ile çerezlik ve yağlık ayçiçeği, \% 3.5 ile yonca ve \% 1.7 ile nohut, takip etmektedir. Geri kalan kısmı da diğer tarla bitkileridir. Bilecik ilinde tarım alanlarının \% 9.2'si (11.476 ha) nadasa bırakılmakta, \% 32.32'lik (40.436 ha) kısmı ise keleme olarak tabir edilmektedir [6] (Tablo 2). Keleme alan; miras anlaşmazlıkları, parsellerin çok parçalı olması, arazi sahiplerinin büyük şehirlere göç etmesi, domuz zararı vb. durumlardan dolayı uzun süreden beri hiç ekilemeyen alanlardır.

Tablo 2. Bilecik il geneli ürün gruplarının ekim alanı ve üretim miktarları*

\begin{tabular}{lcc}
\hline Ürün Grupları & Ekiliş (ha) & \% Dağılım \\
\hline Tarla Ziraatı Alanları & 50.724 & 40.5 \\
Sebze Alanı & 6.362 & 5.09 \\
Örtüaltı Sebze Alanı & 385 & 0.3 \\
Meyve Alanı & 14.037 & 11.2 \\
Nadas Alanı & 11.476 & 9.2 \\
Kavaklık Alan & 1.658 & 1.39 \\
Keleme Alan & 40.436 & 32.32 \\
Toplam Tarım Alanı & 125.081 & 100 \\
\hline
\end{tabular}

* Bilecik İl 2018 yılı Tarım ve Orman Müdürlüğü Brifingi

\section{B. Yem bitkileri ekim alanlarl ve üretim miktarları}

Bilecik’te işlenebilir tarım alanları içerisindeki yem bitkileri ekim oranı \% 5.29'dur. İlde yetiştirilen yem bitkileri Tablo 3 'te görüldüğü üzere yonca, korunga, silajlık mısır, fiğg, yulaf ve tritikaledir. Ayrıca tabloda yer almayan 25 ha alanda ise hayvan şalgamı ekilmektedir. İl geneli incelendiğinde en büyük ekim alanına sahip yem bitkisi yonca olup, bunu sirasıyla 1.449 ha ile yulaf, 1.140 hektar ile fiğ, 665 hektar ile silajlık misır, 403 hektar ile korunga ve 111 hektar ile tritikale takip etmektedir. İlde 37.063 ton yonca, 4.948 ton korunga, 8.704 ton fiğ ve 4.203 ton yulaf kuru otu elde edilmektedir (Tablo 3). Bilecik'te ayrıca 14 ton fiğg, 216 ton tritikale ve 1100 ton yulaf dane üretimi yapılmaktadır. Silajlık mısır üretimi ise 29.085 tondur [6] (Tablo 3). 
Tablo 3. Bilecik ili ilçeler bazında yem bitkisi ekim alanları ile ot ve silaj üretimleri

\begin{tabular}{|c|c|c|c|c|c|c|}
\hline \multirow{2}{*}{ İlçeler } & \multicolumn{2}{|c|}{ Yonca } & \multicolumn{2}{|c|}{ Korunga } & \multicolumn{2}{|c|}{ Silajlık Mısır } \\
\hline & $\begin{array}{r}\text { Alan } \\
\text { (ha) }\end{array}$ & $\begin{array}{c}\text { Üretim } \\
\text { (ton) }\end{array}$ & $\begin{array}{r}\text { Alan } \\
\text { (ha) }\end{array}$ & $\begin{array}{c}\begin{array}{c}\text { Üretim } \\
\text { (ton) }\end{array} \\
\end{array}$ & $\begin{array}{r}\text { Alan } \\
\text { (ha) }\end{array}$ & $\begin{array}{c}\text { Silaj Üretim } \\
\text { (ton) }\end{array}$ \\
\hline Bozüyük & 305 & 9.455 & 242 & 3.509 & 95 & 5.752 \\
\hline Gölpazarı & 110 & 1.978 & 55 & 550 & 115 & 4.813 \\
\hline İnhisar & - & - & - & - & - & - \\
\hline Merkez & 425 & 6.800 & 38 & 205 & 160 & 6.650 \\
\hline Osmaneli & 175 & 3.500 & 20 & 300 & 108 & 5.040 \\
\hline Pazaryeri & 305 & 7.625 & 19 & 190 & 72 & 2.780 \\
\hline Söğüt & 187 & 2.805 & 4.5 & 18 & 15 & 450 \\
\hline Yenipazar & 245 & 4.900 & 25 & 176 & 100 & 3.600 \\
\hline İl Geneli & 1.7520 & 37.063 & 403 & 4.948 & 665 & 29.085 \\
\hline \multirow[b]{2}{*}{ İlçeler } & \multicolumn{2}{|c|}{ Fiğ } & \multicolumn{2}{|c|}{ Yulaf } & \multicolumn{2}{|c|}{ Tritikale } \\
\hline & $\begin{array}{r}\text { Alan } \\
\text { (ha) }\end{array}$ & $\begin{array}{c}\text { Üretim } \\
\text { (ton) }\end{array}$ & $\begin{array}{r}\text { Alan } \\
\text { (ha) }\end{array}$ & $\begin{array}{c}\text { Üretim } \\
\text { (ton) }\end{array}$ & $\begin{array}{r}\text { Alan } \\
\text { (ha) }\end{array}$ & $\begin{array}{c}\text { Üretim } \\
\text { (ton) }\end{array}$ \\
\hline Bozüyük & 291 & 2.475 & 140 & 455 & 28 & 378 \\
\hline Gölpazarı & 153 & 712 & 384 & 960 & - & - \\
\hline İnhisar & 50 & 500 & - & & - & - \\
\hline Merkez & 250 & 1.793 & 160 & 400 & 4 & - \\
\hline Osmaneli & 70 & 560 & - & - & 6.5 & 65 \\
\hline Pazaryeri & 85 & 264 & 35 & 118 & 21 & - \\
\hline Söğüt & 240 & 2.400 & 80 & 320 & 46 & - \\
\hline Yenipazar & - & - & 650 & 1.950 & 6 & - \\
\hline İ Geneli & 1.139 & 8.704 & 1.449 & 4.203 & 111.5 & 443 \\
\hline
\end{tabular}

İlçeler bazında en fazla korunga ekim alanı ve üretimi Bozüyük ilçesinde görülmektedir. Bu durum diğer ilçelere göre Bozüyük'ün daha kurak bir iklime sahip olmasından kaynaklanmaktadır. En fazla yonca ekim alanına ise 425 ha ekim alanı ile Merkez ilçesinde görülmektedir (Tablo 3).

Bilecik’te yem bitkisi ekim alanlarına yönelik olarak her yıl İl Özel İdare kaynağından yem bitkisi tohumluğu alımı yapılmaktadır. Bu kapsamda 2018 yılında tohumluğun \% 60'ının çiftçiler tarafından karşılanması kaydıyla yonca ve Macar fiği tohumu dağıtılmıştır.

\section{Yem bitkileri destekleri}

Hayvancılığın Desteklenmesi Hakkında Karar gereği 2018 yılında Bilecik ilinde 799 çiftçiye 1.410.725,84 TL yem bitkisi desteği verilmiştir. Desteğe tabi alan 2.112 ha alandır. En fazla destek merkez ilçede yer alan çiftçilere yapılmış olup, destek miktarı ise 371 milyondur. En fazla çiftçi sayısının bulunduğu Yenipazar (187) ilçesine yapılan destek miktarı ise 296 milyon civarında olmuştur [5, 6] (Tablo 4).

Tablo 4. Bilecik ili 2018 yılı yem bitkileri destekleme miktarları*

\begin{tabular}{|c|c|c|c|c|c|c|c|}
\hline İlçeler & $\begin{array}{l}\text { Çiftçi } \\
\text { Sayısı }\end{array}$ & $\begin{array}{l}\text { Desteklenen Alan } \\
\text { (ha) }\end{array}$ & $\begin{array}{l}\text { Yonca } \\
\text { (ha) }\end{array}$ & $\begin{array}{l}\text { Korunga } \\
\text { (ha) }\end{array}$ & Fiğ (ha) & $\begin{array}{c}\text { Silajlık } \\
\text { Misır (ha) }\end{array}$ & $\begin{array}{c}\text { Toplam Destek } \\
\text { Miktarı (TL) }\end{array}$ \\
\hline Bozüyük & 83 & 205,99 & 5,66 & 4,07 & 155,79 & 14,20 & $131.546,84$ \\
\hline Gölpazarı & 108 & 245,20 & 6,83 & 0,12 & 49,77 & - & $147.039,43$ \\
\hline İnhisar & 23 & 50,35 & - & - & 50,34 & - & $30.206,76$ \\
\hline Merkez & 149 & 485,85 & 10,50 & 3,25 & 73,72 & 85,94 & $371.127,32$ \\
\hline Osmaneli & 65 & 166,79 & 4,35 & & 10,20 & 11,19 & $117.066,43$ \\
\hline Pazaryeri & 100 & 241,30 & 10,80 & 0,60 & 61,73 & 18,22 & $157.490,17$ \\
\hline Söğüt & 84 & 272,96 & 37,30 & 0,25 & 175,57 & 2,17 & $159.994,67$ \\
\hline Yenipazar & 187 & 443,56 & 6,96 & 2,60 & 25,70 & 23,17 & $296.254,22$ \\
\hline Toplam & 799 & $2.112,9$ & 82,4 & 10,89 & 602,82 & 154,89 & $1.410 .725,84$ \\
\hline
\end{tabular}




\section{D. Çayır mera varlığı}

İlde toplam arazi varlığının \% 1.4'ünü, toplam tarım alanlarının ise \% 4.80'ini çayır mera alanları oluşturmaktadır. Ülke genelindeki toplam 19.042.278 BBHB başına, 14.617 milyon hektar çayır mera alanı düşerken (0.76ha/BBHB), Bilecik ilinde 44.997,91 BBHB başına 6.008,50 hektar çayır mera alanı $(0,13$ ha/BBHB) düşmektedir [5, 6] (Tablo 5). İlçeler itibariyle çayır mera alanlarına baktığımızda, Bozüyük ve Söğüt ilçelerinde mera varlığının daha fazla olduğunu görmekteyiz. Bozüyük ve Söğüt ilçeleri diğer ilçelere oranla alan olarak daha büyük ve topoğrafik koşulların daha müsait olması sebebiyle çayır mera alanları daha fazladır.

Tablo 5. Bilecik ilçelerinin çayır mera alanları ve kuru ot üretimleri

\begin{tabular}{lcccc}
\hline \multirow{2}{*}{ İlçeler } & \multicolumn{2}{c}{ Çayır Mera Alanları } & Toplam Tarım & $\begin{array}{c}\text { Mera Alanlarının Tarım } \\
\text { Alanlarına Oranı (\%) }\end{array}$ \\
\cline { 2 - 3 } & Alanı (ha) & Üretilen Kuru Ot (ton) & & 12.28 \\
\hline Bozüyük & $2.004,76$ & $1.002,38$ & $16.320,9$ & 3.87 \\
Gölpazarı & 428,30 & 214,15 & $11.069,5$ & 3.68 \\
İnhisar & 751,76 & 375,88 & $2.040,3$ & 0.77 \\
Merkez & 108,99 & 54,50 & $14.026,1$ & 4.03 \\
Osmaneli & 499,60 & 249,80 & $12.370,1$ & 5.21 \\
Pazaryeri & 487,67 & 243,84 & $9.351,8$ & 17.91 \\
Söğ̈üt & $1.549,47$ & 774,74 & $8.649,4$ & 1.94 \\
Yenipazar & 177,90 & 88,95 & $9.157,4$ & 7.24 \\
İl Geneli & $6.008,50$ & $3.004,25$ & $82.985,5$ & 38.44 \\
Ülke Geneli & $14.617,00$ & $14.000,00$ & $38.002,00$ & \\
\hline
\end{tabular}

\section{E. Çayır mera alanlarında yapılan çalışmalar}

Bilecik ilinde 6.008,5 hektar mera alanın tespit çalışmaları neticesinde 5.774,45 hektar alanında tahdit ve 4.396,06 hektar alanda ise tahsis çalışmaları tamamlanmıştır. İlçeler bazında en fazla tahsis işlemi tamamlanan İnhisar iken, bunu \% 99.5 ile Söğüt takip etmiştir [5, 6] (Tablo 6).

Tablo 6. Mera kanununa göre yapılan tespit tahdit ve tahsis çalışmalarında Bilecik ilinin son durumu

\begin{tabular}{lcccc}
\hline İlçeler & $\begin{array}{c}\text { Mera Tespit Alanı } \\
\text { (ha) }\end{array}$ & $\begin{array}{c}\text { Mera Tahdit (Tescil) } \\
\text { Alanı } \\
(\mathbf{h a})\end{array}$ & $\begin{array}{c}\text { Tahsis Yapılan } \\
\text { Alan } \\
\text { (ha) }\end{array}$ & $\begin{array}{c}\text { Tahsis Tamamlanma } \\
\text { Oranı } \\
(\%)\end{array}$ \\
\hline Bozüyük & $2.004,76$ & $2.005,16$ & 764,88 & 38 \\
Gölpazarı & 428,30 & 150,78 & 86,17 & 57 \\
İnhisar & 751,76 & 749,88 & 749,88 & 100 \\
Merkez & 108,99 & 106,851 & 79,44 & 74 \\
Osmaneli & 499,60 & 512,83 & 507,08 & 99 \\
Pazaryeri & 487,67 & 480,39 & 443,98 & 92 \\
Söğüt & $1.549,47$ & $1.588,22$ & $1.588,2$ & 99.5 \\
Yenipazar & 177,90 & 183,30 & 181,30 & 99 \\
İ Geneli & $6.008,50$ & $5.777,44$ & $4.396,06$ & 76 \\
\hline
\end{tabular}

\section{BİLECİK İLİ HAYVAN VARLIĞI}

Bilecik ilinde 41.826 adet büyükbaş ve 148.261 adet küçükbaş hayvan varlığı mevcuttur. Büyükbaş hayvanların 27.706'sı kültür, 12.874'ü melez, 1.039'u yerli ırk sığır olup 207'si ise mandadır. Büyükbaş hayvan varlığı toplam büyükbaş sayısına oranlandığında; kültür \% 66.24'ü, melez \% 30.77'si, yerli \% 2.48'i ve manda ise \% 0.49'u oluşturmaktadır. İlde toplam148.261 küçükbaş hayvan sayısının 105.590’1 koyun (\% 71), 42.671'i (\% 29) ise keçidir [5, 6]. İlçeler itibariyle BBHB eşdeğerindeki hayvan varlıklarına bakıldığında ilk üç sırayı 10 813,6 BBHB değeriyle Merkez ilçe, 9.271,18 BBHB ile Bozüyük ve 5.579,33 BBHB ile Söğüt ilçesi almaktadır. $\mathrm{Bu}$ üç ilçenin toplam hayvan varlığı, Bilecik genelinin \% 57.06'sını oluşturmaktadır. Bu ilçeleri sırasıyla 
Pazaryeri, Osmaneli, Gölpazarı, Yenipazar ve İnhisar ilçeleri takip etmektedir. BBHB değeri ile baktığımızda ülkemizin hayvan varlığının \% 0.25'ini Bilecik'te bulunduğunu görmekteyiz [5, 6] (Tablo 7).

Tablo 7. Bilecik ili ve ilçeleri hayvan varlı̆̆ı

\begin{tabular}{|c|c|c|c|c|}
\hline İlçeler & Büyükbaş (baş) & Küçükbaş (baş) & BBHB* & Oran (\%) \\
\hline Bozüyük & 7.712 & 32.712 & $9.271,18$ & 20.64 \\
\hline Gölpazarı & 4.555 & 13.733 & $4.788,50$ & 10.64 \\
\hline İnhisar & 289 & 8.242 & 907,81 & 2.01 \\
\hline Merkez & 10.032 & 31.690 & $10.813,78$ & 24.03 \\
\hline Osmaneli & 5.078 & 13.519 & $5.124,86$ & 11.38 \\
\hline Pazaryeri & 5.865 & 13.373 & $5.271,60$ & 11.71 \\
\hline Söğüt & 4.249 & 32.223 & $5.579,33$ & 12.39 \\
\hline Yenipazar & 4.046 & 2.769 & $3.240,85$ & 7.20 \\
\hline İl Geneli & 41.826 & 148.261 & $44.997,91$ & 100 \\
\hline Ülke & 17.220 .903 & 46.117 .399 & 19.042 .278 & 100 \\
\hline
\end{tabular}

\section{IV. ÜRETILLEN KABA YEMIN İHTIYACI KARŞILAMA ORANI}

Bilecik ilinin yem bitkisi ekim alanları ve çayır ve mera alanlarından elde edilen kaba yemin, mevcut hayvan varlığının ihtiyacını karşılama oranı değerlendirildiğinde, ilde yem bitkileri ve silaj üretiminden 63.344 ton, çayır mera alanlarından ise 6.000 ton olmak üzere toplam 69.344 ton kaba yem elde edilmektedir. İldeki toplam hayvan varlığının BBHB olarak değeri 44.997 olup, mevcut hayvan varlığının bir yıllık kaba yem ihtiyacı (44.997 x 12.5 kg kuru ot x 365 gün) ise 205.302 ton/yıl'dır. İldeki kaba yem açığı 135.958 ton olup, üretilen kaba yemin ihtiyacı karşılama oranı ise \% 33.77'dir (Tablo 8).

Tablo 8. Bilecik ilinde üretilen toplam kaba yemin mevcut hayvan varlığının ihtiyacını karşılama oranı

\begin{tabular}{|c|c|}
\hline Çayır ve meralardan elde edilen kuru ot & 6.000 ton \\
\hline Yem bitkisi ekilişinden elde edilen kuru ot & 55.361 ton \\
\hline Silaj ekilişinden elde edilen kuru ot değeri & 7.983 ton \\
\hline Toplam & 69.344 ton \\
\hline Toplam hayvan varlığı & 44.997 ВBHB \\
\hline Gerekli kaba yem ihtiyacı & 205.302 ton \\
\hline Kaba yem açı̆̆1 & 135.958 ton \\
\hline Üretilen kaba yemin ihtiyacı karşılama oranı & $\% 33.77$ \\
\hline
\end{tabular}

\section{YEM BITTKİLERİ TARIMI SORUNLARI VE ÇÖZÜM ÖNERİLERİ}

Ülkemiz hayvancılığının en temel sorunlarının başında kaba yem açı̆̆ı gelmektedir. Kaliteli kaba yem kullanımı, ekonomik ve sürdürülebilir bir hayvancılık açısından çok önemlidir. Nitekim hayvanların yeteri kadar kaba yemle beslenememesi sonucunda et, süt gibi hayvansal ürün miktarlarında düşüşler meydana gelmektedir. $\mathrm{Bu}$ nedenlerden dolayıdır ki, hayvancılık işletmelerinde yem bitkileri üretimi kaçınılmaz görülmektedir [7].

Yem bitkileri üretiminin önemini belirten bu faydalarına karşın tarımının yapılmasında birçok sorunla karşılaşılmaktadır. Bilecik ili için de geçerli olan bu sorunları ve sorunlara karşı çözüm önerilerini şu şekilde siralayabiliriz:

Ülkemizde olduğu gibi, hayvansal üretimin olmazsa olmazı kaba yem gereksinimi bilincine yeterince varılamamış olması, Bilecik çiftçisinin de en önemli sorunlarının başında gelmektedir. Nitekim kaba yemler, hayvanların verim ömrünün arttırılması, beslenmeye bağlı hastalıkların meydana gelme olasılığını büyük ölçüde azaltması, hayvanların mekanik tokluğunun yaratılmasında kullanılması ve geviş getiren hayvanlarda yemlemeye bağlı olarak meydana gelen ishalin ortadan kaldırılmasında en güvenli ve ucuz olan yoldur. Kaba yemin bu kadar önemli olduğunun farkında olmayan hayvan yetiştiricileri, daha pahalı olan kesif yem ile hayvan besleme yoluna gitmekte ve bunun sonucunda da yem girdilerindeki artışla beraber, hayvanların sağlığı ve 
verimleri de olumsuz etkilenmektedir. Bu itibarla yapılacak ilk iş olarak kaliteli kaba yemlerin hayvan besleme açısından ne denli önemli olduğu konusunda hayvan yetiştiricilerin bilinçlendirilmesi gelmektedir.

İlde nadasa bırakılan arazi miktarı 11.476 hektardır. Toplam tarımsal arazi varlığının 125.081 hektar olduğu düşünüldüğünde tarımsal arazi varlığının \% 9.2'lik bir kısım her yıl nadasa bırakılmaktadır. Nadasın dışında ise tarım arazisi olduğu halde yörede keleme olarak adlandırılan 40.436 ha arazi ise uzun yıllardır hiç ekilmemektedir. Bu alan tarımsal arazi varlığının \% 32.32'sine denk gelmektedir. Nadas ve keleme araziler \% 41.52 ile toplam tarımsal arazi varlığında ciddi bir yer tutmaktadır. Bu alanlar yem bitkileri ekimi ile değerlendirildiğinde, kaba yem üretimine ve ilimiz hayvancılığına büyük katkı sağlayacağı düşünülmektedir.

\section{KAYNAKLAR}

[1] Önal Aşçıı, Ö., \& Acar, Z. (2018). Kaba Yemlerde Kalite. TMMOB Ziraat Mühendisleri Odası, Ankara, 112.

[2] Gülümser, E. (2016). Orta Anadolu Koşullarında Macar Fiği+Tahıl Karışımlarının ve Arkasından Ekilen Silajlık Mısırın Verim ve Kalitesinin Belirlenmesi. Doktora Tezi, Ondokuz Mayıs Üniversitesi, Fen Bilimleri Enstitüsü, Tarla Bitkileri Anabilim Dalı, Samsun.

[3] Sabanc1, C. O. (2009). Baklagil Yem Bitkileri, Yüzüncü Yıl Üniversitesi Vakfı Yayınları, No: 2, s. 69, Van.

[4] Akdeniz, H., Yılmaz, İ., Andiç, N., \& Zorer, Ş. (2004). Bazı Mısır Çeşitlerinde Verim ve Yem Değerleri Üzerine Bir Araştırma. Yüzüncü Yıl Üniversitesi. Ziraat Fakültesi, Tarım Bilimleri Dergisi, 14(1): 47-51.

[5] Anonymous, (2018a). https://www.turkiye.gov.tr/turkiye-istatistik-kurumu-baskanligi-tuik. (Ziyaret tarihi: 05.08.2019).

[6] Anonymous, (2018b). Tarım ve Orman Bakanlığı, Bilecik İl Müdürlüğü 2018 Brifingi.

[7] Mut, H., Geze, M., Gülümser, E., Başaran, U., Çopur Doğrusöz, M., \& Ayan İ. (2016). Yozgat'ta Yem Bitkileri Tarımının Genel Durumu. I. Uluslararası Bozok Sempozyumu, 5-7 Mayıs, Yozgat. 